\title{
Induction of Somatic Embryogenesis in Vulnerable Medicinal Plant Hedychium spicatum Buch-Ham ex Smith
}

\section{Dinesh Giri* and Sushma Tamta ${ }^{1}$}

Plant Tissue Culture Laboratory, Department of Botany, D.S.B. Campus Kumaun

University, Nainital Uttrakhand-263002, India

Key words: Direct somatic embryogenesis, Hedychium spicatum, Synthetic seed

\begin{abstract}
This protocol has been developed for somatic embryogenesis in Hedychium spicatum. Simultaneously, a method has also been developed for the production of synthetic seeds by using somatic embryos. Direct somatic embryos were developed on cotyledon explants of zygotic embryos on MS supplemented with high concentration of NAA $(20.0 \mu \mathrm{M})$. Induction of secondary embryogenesis was best in 2,4-D supplemented medium fortified with activated charcoal. Germination of somatic embryos was enhanced by using $\mathrm{GA}_{3}$. Besides this, round and semi-hard beads of somatic embryos (synthetic seeds) could be produced by using $2 \% \mathrm{Na}$-alginate and $100 \mathrm{mM}$ calcium chloride and more than $30 \%$ germination of synthetic seeds was achieved in MS. Well acclimated plants produced via somatic embryogenesis and/or synthetic seeds were transferred to field where more than $60 \%$ survived. This simple study enabled us to obtain a number of plantlets throughout the year each cycle requiring a short period of time. Besides propagation, this study provided an ex situ method for conservation of this vulnerable Himalayan species.
\end{abstract}

\section{Introduction}

Somatic embryos and synthetic seeds (embryos encapsulated in an artificial solidified medium endosperm) hold potential for large scale clonal propagation of superior genotypes of heterogeneous plants of economic interest (Redenbaugh et al. 1993, Mamiya and Sakamoto 2001). Somatic embryos are widely considered to be of single cell origin; hence advantageous for transformation studies. Moreover, the process of somatic embryogenesis offers a means to propagate

*Author for correspondence: <giri_gld@rediffmail.com>. ${ }^{1}$ Department of Biotechnology, Bhimtal Campus, Kumaun University, Nainital, Uttrakhand, India. 
large numbers of plants over a short period of time (Giridhar et al. 2004). The concept of production and utilization of synthetic seeds were suggested by Murashige in 1977 (Bajaj 1995, Cry 2000). Synthetic seeds can be produced by packing somatic embryos, shoots or other tissue material in transparent polysaccharide gel containing nutrients (Redenbaugh et al. 1993).

Hedychium spicatum Buch-Ham ex Sm (Zingiberaceae) commonly known as Kapoor Kachri or Ginger lily is a Himalayan monocotyledonous herb. Its rhizome is used in treatment of asthma, acute pain, foul breath, hiccough, vomiting and laxative, stomachic, carminative, stimulant tonic for the brain, in liver complaints diarrhoea (Kirtikar and Basu 1987). Rhizome extracts showed antimicrobial activity against Gram-positive and Gram-negative bacteria (Bisht et al. 2006). Recently, the crude extract of the rhizome has been used in the preparation of an anticancerous drug, namely PADMA-28 (Nayab et al. 2004). According to the threat status of IUCN criteria $H$. spicatum has become vulnerable (Samant and Pant 2006). It is also listed in near threatened category of the essential oil bearing plants (Kemp 2003, Samant and Palni 2000). It is also reported that $H$. spicatum is commercially exploited from its natural area (Samant et al. 2007).

The regeneration studies available of this plant are mostly based on rhizome meristem culture (Koul et al. 2005) and shoot tip culture (Badoni et al. 2010, Giri and Tamta 2011). A few reports on somatic embryogenesis on this genus are available. A survey of literature reveals that there are few studies on somatic embryogenesis in this genus like H. coronarium (Huang and Tsai 2002) and H. muluense (Hamidou et al. 2008). The purpose of this study was to develop a reproducible protocol via direct somatic embryogenesis for $H$. spicatum. Furthermore, production of synthetic seeds and their germination would also be helpful in conserving this high value Himalayan medicinal and aromatic plant.

\section{Materials and Methods}

Seeds of H. spicatum were collected from their natural habitat (Nainital district in Uttarakhand State, India) and brought to the laboratory, separated from spikelets, allowed to air dry at room temperature and then stored at $40^{\circ} \mathrm{C}$ until their use. Seeds were treated with a systemic fungicide - bavistine $(1 \%, \mathrm{w} / \mathrm{v}, 5$ min) and rinsed several times with double distilled water. Then surface sterilized with mercuric chloride $(0.1 \%, \mathrm{w} / \mathrm{v}, 3 \mathrm{~min})$ in aseptic conditions and again rinsed several times with sterile double distilled water before inoculation on MS (PGR-free) for germination. Seeds started germinating after a week of inoculation. Cotyledons were detached from the germinating zygotic embryos after 18 days of inoculation and used for induction of somatic embryogenesis. 
Towards this objective, MS was supplemented with NAA $(0.5-30.0 \mu \mathrm{M})$. MS without NAA served as control.

Primary somatic embryos (PSEs) were transferred to MS supplemented with NAA $(0.5-30.0 \mu \mathrm{M})$ or 2, 4-D; $1.5-15.0 \mu \mathrm{M}$ with or without AC, $0.1 \%$, w/v for formation and multiplication of secondary somatic embryos (SSEs).

Secondary somatic embryos were transferred to MS supplemented with different concentrations of $\mathrm{GA}_{3}(1.0-7.5 \mu \mathrm{M})$ for further maturation and germination. MS without $\mathrm{GA}_{3}$ served as control.

The medium was solidified with $0.8 \%(\mathrm{w} / \mathrm{v})$ agar. The $\mathrm{pH}$ of the medium was adjusted to 5.8 prior to autoclaving at $121^{\circ} \mathrm{C}, 15 \mathrm{lb}$ psi for $20 \mathrm{~min}$. Approximately $20 \mathrm{ml}$ (in test tube) or $100 \mathrm{ml}$ (in $250 \mathrm{ml}$ Erlenmeyer flask) culture medium was used for each experiment. Each treatment was replicated 15 times and all experiments were repeated twice. Cultures were maintained in a culture room having $16 / 8 \mathrm{hrs}$ (light/dark) photoperiod at $25 \pm 1^{\circ} \mathrm{C}$. Observations were made at regular interval.

With the aim of producing synthetic seeds, somatic embryos (size $>4-6 \mathrm{~mm}$ and opaque in color) were removed from embryo clusters and immersed in autoclaved sodium alginate (1, 2, 3 and $4 \%, w / v)$ solutions. Each embryo was agitated for $4-5 \mathrm{~min}$, picked up using a Pasture pipette and then added in autoclaved solutions of calcium chloride (50.0 and $100.0 \mathrm{mM}$ ) to form beads (encapsulated embryos). Embryos were kept in the solutions for $20-30 \mathrm{~min}$ and occasional shaking was done. The resulting beads were washed thoroughly (three times) with sterilized distilled water and transferred to the culture flasks containing germination medium (MS).

Plantlets, obtained from in vitro germinated somatic embryos after eight weeks of culture of mature embryos on MS supplemented with $2.5 \mu \mathrm{M} \mathrm{GA}_{3}$, were taken out from the flasks and washed carefully with water to remove agar, transferred to small plastic cups ( $8 \mathrm{~cm} \mathrm{ht}, 4 \mathrm{~cm}$ dia) containing soil and farmyard manure $(3: 1, \mathrm{v} / \mathrm{v})$. Initially these cups were kept in the culture room for two weeks for hardening and covered with transparent polythene bags with small holes for air ventilation to ensure high humidity at initial stages. Then these polythene bags were removed and the cups were transferred to polyhouse for further acclimation. Well grown plants were transferred to field in the departmental nursery after four weeks.

Data were subjected to statistical analysis; standard error (SE), Dunnett t-test (2-sided) and ANOVA were calculated following Snedecor and Cochran (1967). 


\section{Results and Discussion}

Seeds cultured on MS (PGR-free) exhibited $80 \%$ germination. Seeds started germinating after a week of inoculation and took 18 days for germination. Induction of somatic embryogenesis was observed during regular subculturing of cotyledons on MS supplemented with NAA. Globular structures were found to develop directly on cotyledons after four weeks of culture. Although all the concentrations of NAA were able to induce somatic embryogenesis (Fig. 1) the higher concentration of NAA $(20.0 \mu \mathrm{M})$ showed better response. It is able to induce up to $79.99 \%$ somatic embryogenesis (Figs 1 and 3). Embryos obtained initially were called as primary somatic embryos (PSEs). NAA when applied with BA, was more suitable than 2, 4-D alone for somatic embryo induction from cotyledons derived from zygotic embryos. However, in the present study the higher concentration of NAA alone was capable of inducing direct somatic embryos.

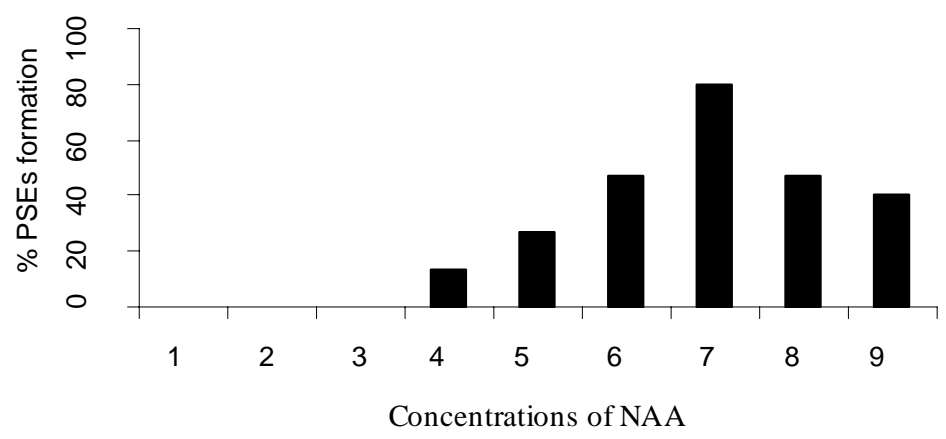

Fig. 1. Effect of different concentrations of NAA on somatic embryogenesis in H. spicatum 1. On $X$ axis - concentration of NAA (in $\mu \mathrm{M})$ represented by numbers $(1=$ Control, $2=$ $0.5,3=2.5,4=5.0,5=10,6=15$ and $7=20,8=25$ and $9=30)$. 2 . On $Y$ axis - Per cent primary somatic embryogenesis.

When these PSEs were transferred to MS supplemented with NAA (0.5 - 30.0 $\mu \mathrm{M})$ or 2, 4-D (1.5 - 15.0 $\mu \mathrm{M})$ with or without activated charcoal for the formation of secondary somatic embryos (SSEs), PSEs showed a poor response in NAA supplemented MS (data not shown), when PSEs were sub-cultured in the same medium, they showed negligible secondary somatic embryogenesis. However, when these PSEs were transferred to MS supplemented with various concentrations of 2, 4-D, they multiplied and secondary somatic embryos (SSEs) were formed in all the concentrations of 2, 4-D (Fig. 2). Here the maximum percentage (73.33) of SSEs were achieved in $10.0 \mu \mathrm{M} 2$, 4-D (Fig. 3B,C). 
Somatic embryos were transferred to MS supplemented with different concentrations of $\mathrm{GA}_{3}(1.0-7.5 \mu \mathrm{M})$ for further maturation and germination. Although somatic embryos were germinated in all the treatments including control (MS without $\mathrm{GA}_{3}$ ) but the germination percentage and average time taken for germination varied among various concentrations of supplements (Table 1). However, it was $2.5 \mu \mathrm{M} \mathrm{GA}_{3}$, which was able to induce maximum per cent germination (88.88), means conversion of somatic embryos to plantlets within 19 days of inoculation (minimum time required for germination) (Plate $3 \mathrm{D}, \mathrm{E}) . \mathrm{GA}_{3}$ was effective in maturation and germination of somatic embryos. ANOVA summary showed that the per cent germination and average time taken for germination have significant differences (at 1\%) within the concentration of $\mathrm{GA}_{3}$ (Table 1). Embryo germination decreased at low $(\leq 1.0 \mu \mathrm{M})$ or high $(\geq 5.0$ $\mu \mathrm{M})$ concentrations of 2, 4-D.

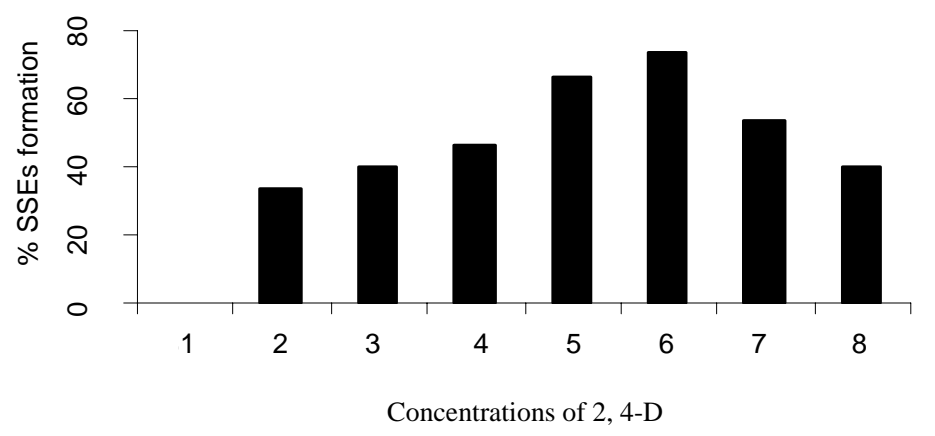

Fig. 2. Effect of different concentrations of 2, 4-D on secondary somatic embryogenesis in H. spicatum. 1. On $\mathrm{X}$ axis - concentration of 2,4-D (in $\mu \mathrm{M})$ represented by numbers $(1=$ Control, $2=1.5,3=2.5,4=5.0,5=7.5,6=10$ and $7=12.5$ and $8=15$ ). 2 . On $Y$ axis - per cent secondary somatic embryogenesis.

Somatic embryos (size $>4-6 \mathrm{~mm}$ ) were removed carefully from embryo clusters and immersed in autoclaved solutions of sodium alginate and calcium chloride. Round and semi-hard beads were formed using 2.0\% Na-alginate and $100.0 \mathrm{mM}$ calcium chloride (Fig. 3F). These synthetic seeds were cultured on MS for germination.

Encapsulation of somatic embryos into calcium alginate beads was seen to be effective in terms of further conversion into plantlets. Synthetic seeds (encapsulated somatic embryos) germinated after four weeks of culture and more than $30.0 \%$ germination of synthetic seeds was recorded (data not shown) and further study is under way. 
Well rooted plantlets (regenerated via somatic embryogenesis and synthetic seeds) were taken out of the culture flasks and the adhering agar was removed; roots were then gently washed before transferring to plastic cups containing soil and farmyard manure. The survival of these plantlets was $60.0 \%$. After eight weeks (two weeks in culture room and four weeks in polyhouse), these plants were transferred to field (Fig. 3G).

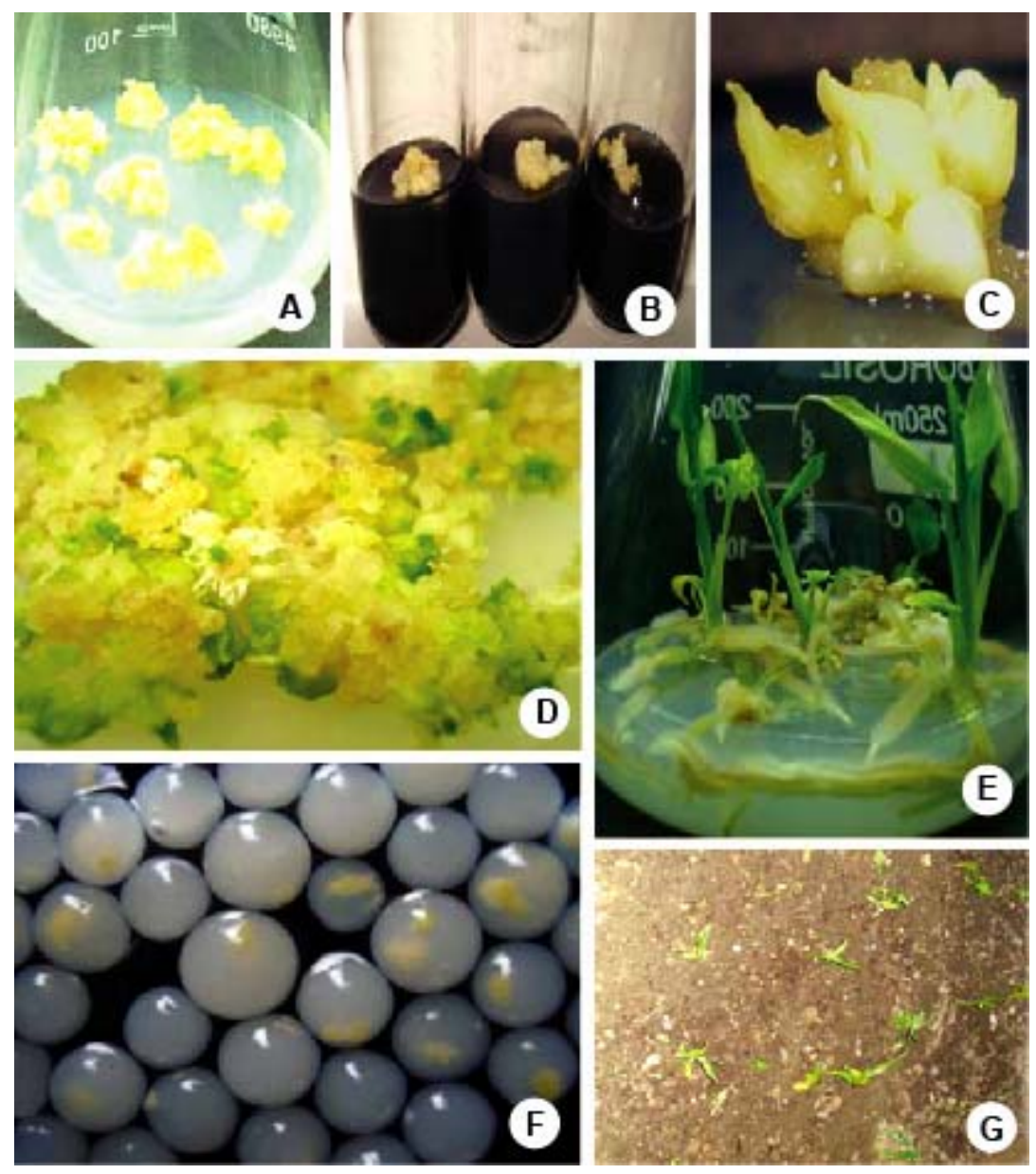

Fig. 3. Somatic embryogenesis and synthetic seed production in H spicatum. A. Primary somatic embryo induction from cotyledons on MS supplemented with NAA $(20 \mu \mathrm{M})$ after four weeks of culture. B. Formation of secondary somatic embryos on MS supplemented with 2-4 D $(10 \mu \mathrm{M})$ and AC $(0.1 \%)$. C. Mature secondary somatic embryos on MS supplemented with 2-4 D $(10 \mu \mathrm{M})$ and AC $(0.1 \%)$ after eight weeks. D. Germination of somatic embryo on MS supplemented with GA3 $(2.5 \mu \mathrm{M})$ after four week. E. Plantlets with well developed root and shoot on MS supplemented with $\mathrm{GA}_{3}(2.5 \mu \mathrm{M})$ after eight week of germination. F. Synthetic seed production. G. Field transfer of plantlets (obtained from somatic embryogenesis and synthetic seeds). 
These results indicate that the higher concentration of NAA is the best treatment for the induction of direct somatic embryogenesis in this species. But in the same medium these PSEs did not respond well and further maturation and development were poor. However, when these were transferred to MS supplemented with 2, 4-D, secondary somatic embryogenesis occurred and percentage was quite good. It was reported that 2, 4-D treatment was more effective for secondary embryo formation from primary somatic embryo than NAA (Kim et al. 2007). To our knowledge, this is the first report to describe somatic embryogenesis and synthetic seed production in $H$. spicatum. In conclusion it took about 28 weeks to obtain plantlets via direct somatic embryogenesis. The production and encapsulation of somatic embryos allows propagation of this species. The protocol developed for regeneration and multiplication of this species through direct somatic embryogenesis and encapsulation can possibly be used for the propagation of this vulnerable medicinal and aromatic Himalayan plant species of high value.

Table 1. Germination of somatic embryo of $H$. spicatum on MS supplemented with $\mathrm{GA}_{3}$.

\begin{tabular}{|c|c|c|c|c|}
\hline $\mathrm{GA}_{3}(\mu \mathrm{M})$ & \multicolumn{2}{|l|}{$\%$ germination } & \multicolumn{2}{|c|}{$\begin{array}{l}\text { Av. time taken for } \\
\text { germination (days) }\end{array}$} \\
\hline 0.0 & \multicolumn{2}{|l|}{$29.62 \pm 3.70$} & \multicolumn{2}{|c|}{$49.00 \pm 1.15$} \\
\hline 1.0 & \multicolumn{2}{|l|}{$48.14 \pm 3.70$} & \multicolumn{2}{|c|}{$30.00 \pm 0.57$} \\
\hline 2.5 & \multicolumn{2}{|l|}{$88.88 \pm 6.41$} & \multicolumn{2}{|c|}{$19.33 \pm 0.88$} \\
\hline 5.0 & \multicolumn{2}{|l|}{$70.36 \pm 7.40$} & \multicolumn{2}{|c|}{$26.66 \pm 1.45$} \\
\hline 7.5 & \multicolumn{2}{|l|}{$44.44 \pm 6.41$} & \multicolumn{2}{|c|}{$29.33 \pm 0.88$} \\
\hline \multicolumn{5}{|c|}{ ANOVA summary } \\
\hline & Sources & $\mathrm{DF}$ & MS & F ratio \\
\hline \multirow[t]{3}{*}{$\%$ germination } & Between group & 04 & 1633.58 & $016.54^{*}$ \\
\hline & Within group & 10 & 0098.76 & \\
\hline & Total & 14 & & \\
\hline \multirow{3}{*}{$\begin{array}{l}\text { Av. time taken } \\
\text { for germination }\end{array}$} & Between group & 04 & \multirow{3}{*}{$\begin{array}{l}0361.93 \\
0003.20\end{array}$} & $113.10^{*}$ \\
\hline & Within group & 10 & & \\
\hline & Total & 14 & & \\
\hline
\end{tabular}

Data represented mean values \pm standard error $(\mathrm{SE})$. Nine somatic embryos per flask (in triplicates) were used. ${ }^{*}$ Level of significance at 0.01 (at 1\%).

\section{Acknowledgment}

The authors thank Head of the Botany Department, Kumaun University, Nainital for providing them necessary facilities in the department. 


\section{References}

Badoni A, Bisht C and Chauhan JS (2010) Micropropagation of Hedychium spicatum Smith using in-vitro shoot tip. Stem Cell 1(1):11-13.

Bajaj YPS (1995) Somatic embryogenesis and synthetic seed. In: Biotechnology in Agriculture and Forestry. Springer-Verlag, Berlin 30.

Bisht GS, Awasthi AK and Dhole TN (2006) Antimicrobial activity of Hedychium spicatum. Fitoterapia 77: 240-242.

Cyr DR (2000) Seed substitutes from the laboratory. In: Seed technology and its biological basis. Black, M. and Bewley, J.D. (Eds.). Sheffield Acad. Press, Sheffield. pp. 326-372.

Giri D and Tamta S (2011) Effect of plant growth regulators (PGRs) on micropropagation of a vulnerable and high value medicinal plant Hedychium spicatum. African J. Biotech. 10(20): 4040-4045.

Giridhar P, Kumar V, Indu EP, Ravishankar GA and Chandrasekar A (2004) Thidiazuron induced somatic embryogenesis in Coffea arabica L. and Coffea canephora P. ex Fr. Acta Bol. Croat. 63(1): 25-33.

Hamidou F, Sakhanokho RY and Kelley KR (2008) First report of plant regeneration via somatic embryogenesis from shoot apex-derived callus of Hedychium muluense Smith. J. Crop Improvement 21(2): 191-2000.

Huang PL and Tsai CC (2002) Micropropagation of Hedychium coronarium Koenig via somatic embryogenesis. J. Chinese Society Hort. Science 48(3): 239-245.

Kemp R (2003) Effect of crdiac rsynchronization on mocardial eficiency and rgional oidative mtabolism. J. Econ. Taxon Bot. 27: 485.

Kim YS, Lim S, Choi YE and Anbazhagan VR (2007) High frequency plant regeneration via somatic embryogenesis in Podophyllum peltatum L., an important source of anticancer drug. Curr. Sci. (Bangalore) 92(5): 662-666.

Kirtikar KR and Basu BD (1987) Indian Medicinal Plants. International Book Distributors, DehraDun. p. 444-2449.

Koul S, Raina V and Sharma SK (2005) Conservation and propagation of high altitude medicinal and aromatic plant: Hedychium spicatum. J. Plant Biochem. and Biotech. 14: 57-59.

Mamiya K and Sakamoto Y (2001) A method to produce encapsulatable units for synthetic seeds in Asparagus officinalis. Plant Cell Tiss. Org. Cult. 64: 27-32.

Nayab R, Aingorn H, Fallavollita L, Sallon S, Mechoulam R, Ginsburg I, Vlodavsky I and Brodt P (2004) PADMA-28, a traditional Tibetan herbal preparation, blocks cellular responses to bFGF and IGF-I. Inflammopharmacology 12(4): 373-89.

Redenbaugh K, Fujii JAA and Slade D (1993) Hydrated coating for synthetic seeds. In: Synseeds. Applications of synthetic seeds to crop improvement. Redenbaugh K. (Ed.). CRC Press, Boca Raton, FL. pp. 35-46.

Samant SS and Palni LMS (2000) Diversity, distribution and indigenous uses of essential oil yielding medicinal plants of Indian Himalayan region. J. Med. Arom. Plant Sci. 22: 671- 684 . 
Samant SS and Pant S (2006) Diversity, distribution, pattern and conservation status of the plants used in liver diseases/ailments in Indian Himalaya region. J. Mountain Science 3: 28-47.

Samant SS, Butola JS and Sharma A (2007) Assessment of diversity, distribution, conservation status and preparation of management plan for medicinal plants in the vatchment srea of Parbati Hydroelectric Project Stage - III in Northwestern Himalaya. J. Mountain Science 14(1): 034-056.

Snedecor GW and Cochran WG (1967) Statistical methods. Oxford and IBH Publishing. New Delhi, India. 